\title{
Lateralized Middle Ear Internal Carotid Artery: a Case Report
}

\author{
Ahmad Yahya Al Ahmary ${ }^{*}$, Mohamed Khamis Tolba Mahmoud Abdalla ${ }^{2 *}$ Mohamed Gamal Aly ${ }^{3}$ and Tamer \\ Marey ${ }^{4}$ \\ ${ }^{1}$ Department of Otorhinolaryngology-Head and Neck, Imam Abdulrahman Al Faisal Hospital (IABFH), Kingdom of Saudi Arabia \\ ${ }^{2}$ Department of Otorhinolaryngology-Head and Neck, Imam Abdulrahman Al Faisal Hospital (IABFH), Kingdom of Saudi Arabia \\ ${ }^{3}$ Department of Otorhinolaryngology-Head and Neck, Imam Abdulrahman Al Faisal Hospital (IABFH), Kingdom of Saudi Arabia \\ ${ }^{4}$ Department of Radiology, Imam Abdulrahman Al Faisal Hospital (IABFH), Kingdom of Saudi Arabia
}

Submission: January 02, 2018; Published: January 09, 2018

*Corresponding authors: ${ }^{1} \mathrm{Ahmad}$ Yahya Al Ahmary, Consultant, Department of Otorhinolaryngology-Head and Neck, Imam Abdulrahman Al Faisal Hospital (IABFH), Dammam, Ministry of National Guard, Health Affairs, Kingdom of Saudi Arabia, Tel: +966 555203372; Email: AhmaryA@ngha.med.sa

${ }^{2}$ Mohamed Khamis Tolba Mahmoud Abdalla, Asst. Consultant Department of Otorhinolaryngology-Head and Neck, Imam Abdulrahman Al Faisal Hospital (IABFH), Dammam, Ministry of National Guard, Health Affairs, Kingdom of Saudi Arabia, Tel: +9660590848077; Email: Mohamed_khameess@yahoo.com

\begin{abstract}
48 year old Saudi female presented to the in ENT clinic in Imam Abd Alrhman Bin Faisal hospital with history of right side tinnitus pulsatile since childhood no history of hearing loss, vertigo, or any other otological symptoms. The patient was medically free with no history of any regular medication. No abnormalities was detected in clinical examination however the pure tone audiogram showed they showed bilateral mild high frequency sensor neural hearing loss. CT scan was and showed the reason of pulsatile tinnitus which was the laterally located bony canal of the right internal carotid artery.
\end{abstract}

Keywords: Pulsatile Tinnitus; Lateralized Internal Carotid Artery; Aberrant Carotid Artery; Sensorinural Hearing Loss

\section{Introduction}

The lateralized internal carotid artery is a variant position the course of the horizontal internal carotid artery (ICA). Lateralized petrous ICA is identified on CT by its extreme postrolateral entrance to the base of the skull and protrusion to the anterior mesotympanum. It can be differentiated from the aberrant ICA that enters the posterior hypotympanum by an enlarged inferior tympanic canaliculus, after that it courses across the inferior cochlear promontory to communicate with the normal horizontal petrous ICA. Lateralized ICA is considered a variation of incidental petrous ICA. Awareness of this variation is crucial in the pre-operative evaluation and planning to avoid fatal vascular injuries [1].

\section{Case Presentation}

a) History: 48 year old female presented to the in ENT clinic in Imam Abd Alrhman Bin Faisal hospital With history of right side tinnitus pulsatile since childhood no history of hearing loss, vertigo, or any other otological symptoms. The patient was medically free with no history of any regular medication.

b) Examination: Bilateral intact tympanic membrane was normal appearance, positive Rinne test bilaterally and Weber central. Examination of nasopharynx and tempromandibular joint was normal. Pure tone audiogram and tyampanogram were done and they showed bilateral mild high frequency sensorinural hearing loss and type A tymapanogram bilaterally.

c) Investigations: CT temporal, MRI petrous and MRA were done and they confirm the presence of lateralized internal carotid artery as it shown in (Figures 1-4).

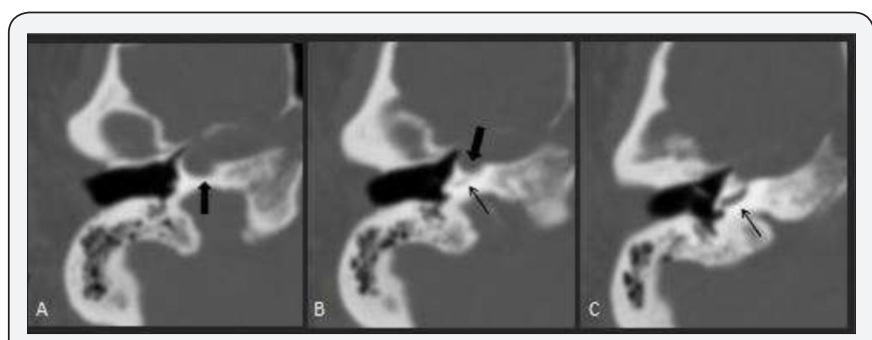

Figure 1: Axial CT sections for the right petrous bone in bone window show lateral orientation of the bony canal of the petrous portion of the right internal carotid artery (Thick black Arrow) which is closely located anterior-medial aspect of the basal turn of the right cochlea (Thin black arrow). 


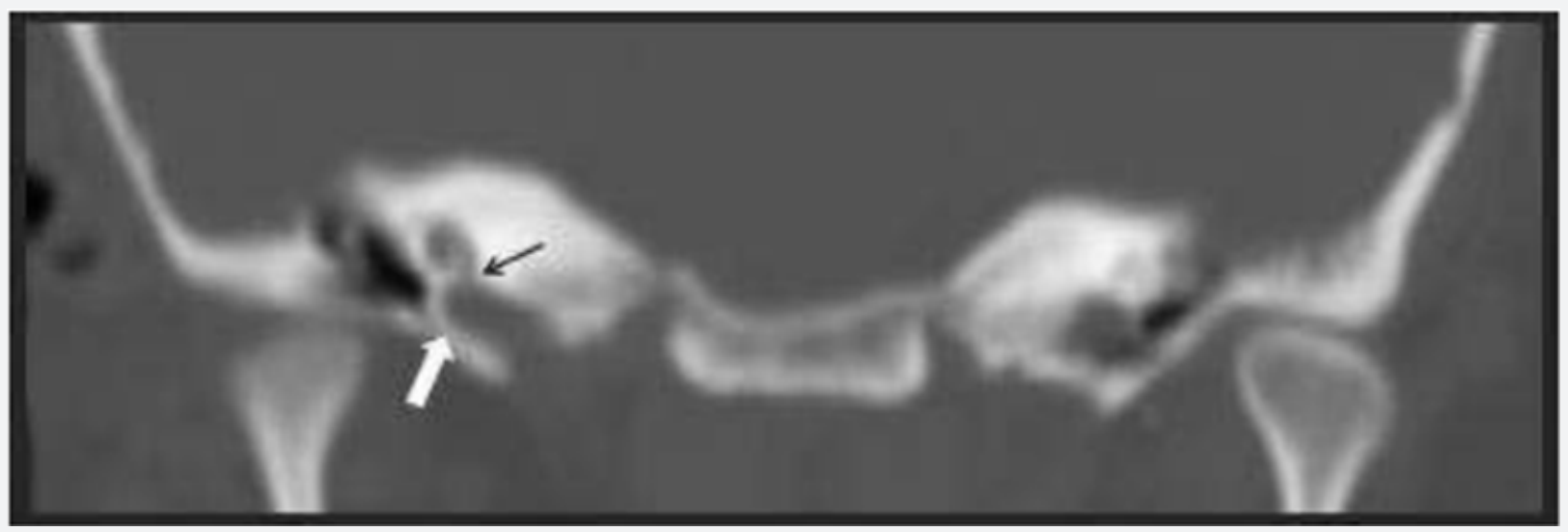

Figure 2: Coronal CT section for the petrous bone demonstrating the close relation of the basal Turn of the cochlea (thin black arrow) to the laterally located bony canal of the right internal Carotid artery (Thick white arrow).

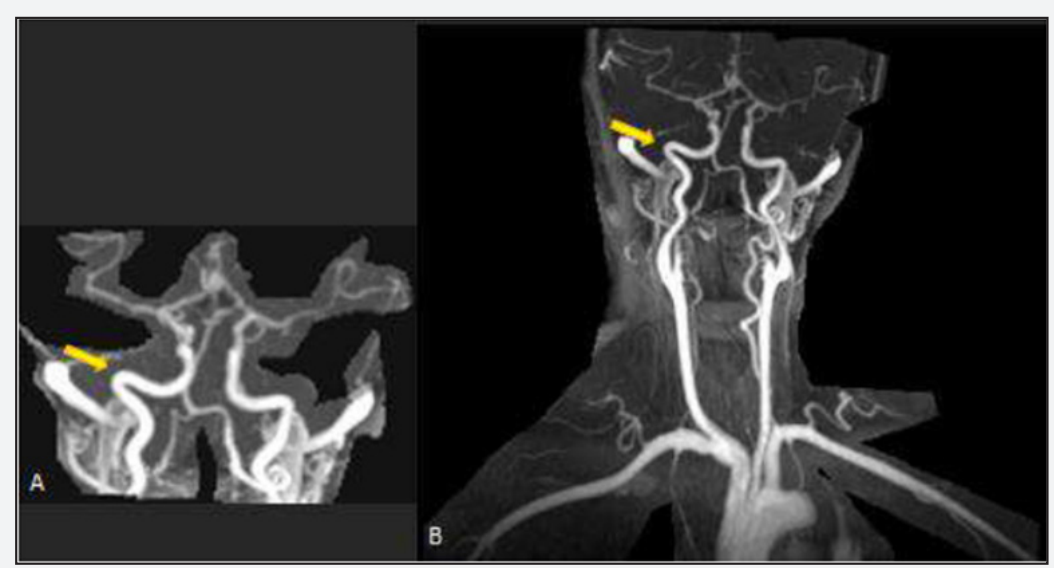

Figure 3: Coronal MIP TOF MRA images for the intera-cranial $(A)$ and neck $(B)$ arteries show Relative lateral peaking of the genu of the petrous portion of the right internal carotid artery (Thick yellow arrow).

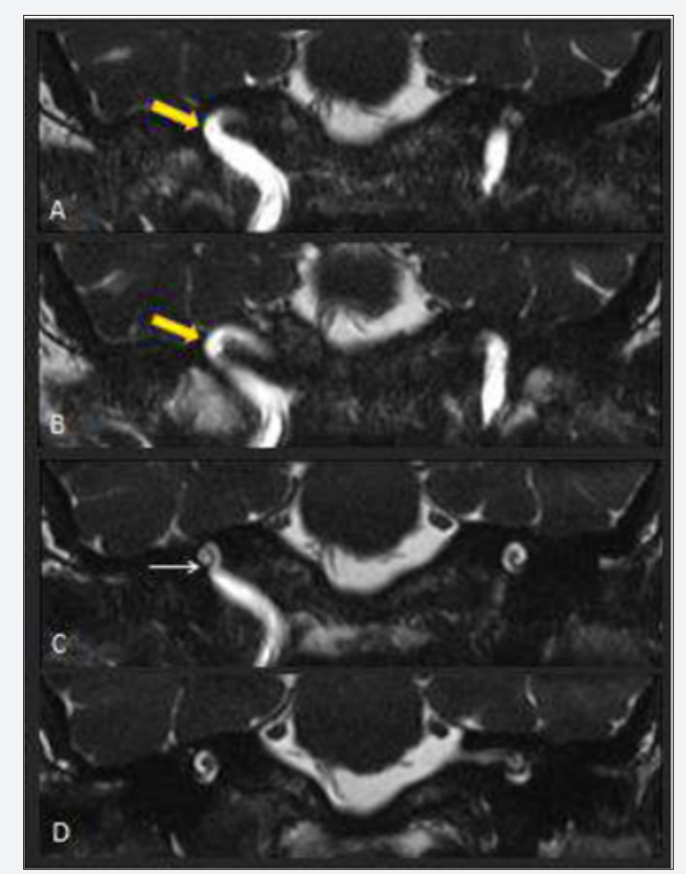

Figure 4: A-D Multiple coronal CISS MRI images illustrating relative lateral orientation of the Genu of the petrous portion of the right internal carotid artery (Thick yellow arrow) and its Intimate relation to the basal turn of the right cochlea (white thin arrow) in C. 


\section{Discussion}

The normal carotid artery course inside the cranium starts by entering the cranium by ascending through the vertical part of the carotid canal in the petrous bone. After that it turns anteromedially to cross the horizontal segment and at the end it ascends again above the foramen lacerurn to go inside the cavernous sinus. The ascending part is infracochlear in its location and carotid plate separates it laterally from the tympanic cavity, a bony shield normally less than $0.5 \mathrm{~mm}$ in its thickness [2]. The normally small caroticotympanic branch of the internal carotid, a remnant of the embryologic hyoid artery, pierces the carotid plate to go inside the tympanic cavity [3]. The inferior Tympanic branch of the ascending pharyngeal artery passes through the inferior tympanic canaliculus to enter the Tympanic cavity. This canaliculus is usually very tiny and it is located on the caroticojugular spine [4]. In the majority of cases, the inferior tympanic canaliculus is not visible CT even those with high resolution.

The caroticotympanic and the inferior tympanic arteries are the suppliers of the medial wall of the tympanic cavity, and they anastomose on the surface of the cochlear promontory $[4,5]$. Lateralized internal carotid artery is an extreme rare vascular variant. In this case, the ICA entering anterior part of the petrous bone and extends lateral to usual normal anatomical position. The genu of the petrous part locates lateral to a line drawn perpendicular to the cochlear basal turn and dehiscence may be found [1]. In the presented case the middle ear internal carotid artery enters the right middle ear more posterolaterally leading to right side pulsatile tinnitus since childhood. Radio logically; there is lateral orientation of the genu of the petrous portion of the right internal carotid artery. Although the lateralized right ICA does not extend lateral to the line drawn perpendicular to the basal turn of the cochlea, it has close proximity to the antero-medial aspect of the basal turn of cochlea. Thus it deems responsible for the patient symptoms.

\section{Important Differential Diagnosis}

Retro tympanic pulsatile tissues such as the aberrant carotid artery, the exposed jugular bulb and the glomus tumor can give the same presentation [6].

\section{References}

1. Glastonbury CM, Harnsberger HR, Hudgins PA, and Salzman Kl (2012) Lateralized petrous internal carotid artery: imaging features and distinction from the aberrant internal carotid artery. Neuroradiology 54(9): 1007-1013.

2. Anson BJ, Wilson JG, Gaardsmoe JP (1938) Air cells of petrous portion of temporal bone in a child four and a half years old: A study based on wax plate reconstructions. Archives of Otolaryngology 27(5): 588-605.

3. Moret J, Delvert C, Bretonneau CH, Lasjaunias P, de Bicêtre CH (1982) Vascularization of the ear: normal-variations-glomus tumors. Journal of neuroradiology. Journal de neuroradiologie 9(3):209-260.

4. Goss CM (edn.) Anatomy of the human body by Henry Gray. $\left(28^{\text {th }}\right.$ edn.) Lea \& Febiger, Philadelphia, USA, 966: 154-158.

5. Lo WW, Solti-Bohman LG, McElveen JT (1985) Aberrant carotid artery: radiologic diagnosis with emphasis on high-resolution computed tomography. Radiographics 5(6): 985-993.

6. Valvassori GE, Buckingham RA (1974) Middle ear masses mimicking glomus tumors: radiographic and otoscopic recognition. Annals of Otology, Rhinology \& Laryngology 83(5): 606-612.

\section{Your next submission with Juniper Publishers will reach you the below assets}

- Quality Editorial service

- Swift Peer Review

- Reprints availability

- E-prints Service

- Manuscript Podcast for convenient understanding

- Global attainment for your research

- Manuscript accessibility in different formats

( Pdf, E-pub, Full Text, Audio)

- Unceasing customer service

Track the below URL for one-step submission https://juniperpublishers.com/online-submission.php 